\title{
Performance Assessment of Bauchi Polytechnics and Technical Colleges Using Quality Assurance Indicators in Nigeria Qualification Framework
}

\author{
Idris Adamu1 \\ ${ }^{1}$ General studies department, College of Education Azare PMB 044 Bauchi State, Nigeria. \\ Email: idrisadamu2623@gmail.com
}

\begin{abstract}
:
Technical and Vocational Education emphases skill acquisition, Quality Assurance in vocational education is concept that is concerned with high performance involved activities with vocational education such as teaching, learning, infrastructures, student's behavior and entire academic process. Good quality education is very necessary in the total development of staff and students which ensures proper development, job prospects and the realization of academic goals and objects. Enhanced and sustained to ensure accountability and improve performance. Higher educational institutions in Nigeria continue to experience carelessly attitude about the use of Quality Assurance to understand the risk they are exposed to poor standard. To address these issues, the study embarked upon to determine the level of performance and difference usability of Quality Assurance in Polytechnics and Technical Colleges in Bauchi state. Quantitative method technique was employed using survey questionnaires, 60 staff both senior and junior within these institutions were selected and a questionnaire distributed for their responses. The data were analyzed using SPSS software. The result reveals that Federal Polytechnic Bauchi and State Polytechnic Bauchi has high level of Performance about Quality Assurance indicators while College of Education Azare has medium level of Performance. College of education Azare has highest mean rank of 29.87 and percentage of $31.8 \%$ obtained from the output result indicated that it has high usability to Quality Assurance, followed by Federal Polytechnic Bauchi with medium usability then State Polytechnic Bauchi has low usability to Quality Assurance. The study concluded by Quality Assurance Unit be made aware to each institution staff to enable recognize the benefits of it. Federal government should give more funding and employ staff to cater the need of Quality Assurance Unit in every institution so that it will help the students to develop their potentialities.
\end{abstract}

Keywords: Quality, Quality Assurance, Technical and vocational education, Performance, Higher institutions.

\section{A. INTRODUCTION}

Todays, interconnected global knowledge intensive economy in advancing dynamism for the advancement of science and technology has affected the manner in which higher education institutions view quality concerns in the higher education sector. Higher education is an important form of investment in human capital. In fact, it can be regarded as a high level or a specialized form of human capital, contribution of which to economic growth is very significant. According to Castell (2001), education is regarded as the engine of development in the new world economy. 
The new millennium is witnessing a lot of transformational challenges in almost all dominions of life including the educational system, bringing about world class standards.

Quality Assurance therefore can be described as a process of managing the educational sector, the services provided to ensure that they are kept at high standard that will positively affect its products. Crosby (2002), highlighted the fact that to realize zero defects in the work process is a difficult one but maintained that it can be achieved through the use of a Quality Assurance system that is laid down procedures on how work should be done to achieve a specified standard. Therefore, this study will provide an imperative clue about the performance assessment of polytechnics and technical colleges based on the level of performance and usability of quality assurance indicators in Bauchi state of Nigeria.

\section{Background of the problem}

An excellent practice of knowledge, Skills, attitude and values are the engines of economic growth and social development of any nation (Goel, 2010). Technical Vocational Education and Training (TVET) holds the key to training the skilled and entrepreneurial workforce needed for the changing technological workforce (Afeti, 2010). Improving the quality and efficiency of education and training based on propose research, given the fact that a significant relationship was established, suffice the study confirmed the alternative hypothesis and consequently upheld the assertion that there is statistical significant relationship between effective performance of technical institutions propose and general performance of Technical and Vocational Education and Training institutions using indicators therefore this study aims to determine the level of performance, differences and applicability of indicators about polytechnics and technical colleges in Bauchi state of Nigeria based on Quality Assurance indicators in Nigerian qualification framework.

\section{Research Objectives}

a. To determine the level of performance of polytechnics and technical colleges using Quality Assurance (QA) indicators.

b. To determine if any, difference between the level of usability of quality assurance indicators within the polytechnics and technical colleges.

\section{Research Questions}

This research question were formulated in order to find answers to the research objectives.

a. What is the level of performance of polytechnics and Technical colleges using quality assurance indicators?

b. What is the differences between the level of usability of Quality Assurance indicator within polytechnics and technical colleges?

\section{Quality in Higher Education}

Quality is an elusive concept. Quality is also a value-laden term. Barnett (1992), define Quality in higher education as different views will bring different priorities to bear upon services and expertise that are provided. Furthermore Barnett (1992) indicated that political, economic and social interplay will occur between somewhat competing in the education field think about quality. Quality means ensuring that students learn what it is they are supposed to learn, an attitude in 
which the culture of the institution becomes less bureaucratic and more focused on the students. It can also be the means providing and using the most efficient way to manage the institution.

\section{Quality Assurance}

Quality assurance refers to continuous process of evaluating the quality of a system, institution or programme. It focuses on enhancing and improving the process that is used to achieve the outcome and directed towards certifying or guaranteeing the quality of an item. It therefore implies that judgments are made against some specified standards of an institution, organisation or professional body. According to Ogunleye (2013), quality assurance is a planned and systematic review process of how goals of an institution are being achieved, enhanced and sustained. The importance of quality assurance is to ensure accountability and improvement of performance. According to Nworgu (2010), Quality is considered as integral and indispensable aspects of all human endeavor's and a veritable tool for decision making in education and other disciplines. It is apt to reflect on trends and challenges in quality assurance in assessment, evaluation and research in Nigeria for better understanding and building of competencies needed for survival in the global age of knowledge economy.

\section{Technical and Vocational Education and Training}

Technical and Vocational Education and Training (TVET) is an education, training or learning activity which provides knowledge, skills and attitudes relevant for self-employment. TVET describes all kinds of formal, non-formal and informal training and learning wherever it occurs institutes, schools, training centres or in the workplace/site of production.

TVET is concerned with the acquisition of knowledge and skills for the world of work. Throughout the course of history, various terms have been used to describe elements of the field that are now conceived as comprising TVET. These include: Apprenticeship Training, Vocational Education, Technical Education, Technical Vocational Education (TVE), Occupational Education (OE), Vocational Education and Training (VET), Professional and Vocational Education (PVE), Career and Technical Education (CTE), Workforce Education (WE), and Workplace Education (WE) (UNESCO-UNEVOC 2000).

\section{Quality Assurance for TVET in Nigeria}

In Nigeria, accreditation is based on individual programmes. The issue of establishment of an institution is a different matter. The Nigerian Constitution has placed education under the concurrent legislative list, which means that both the Federal and state governments can legislate and establish schools and enable them with laws or proclamations as the case may be Muhammad (2007). Moreso, educational standards/quality fall under the exclusive power of the Federal government, there are several Quality Assurance Agency were establishment such as National University Commission (NUC), and National Board for Technical Education (NBTE), National Business and Technical Examination Board (NABTEB). National Commission for Colleges Education (NCCE). Their roles include the accreditation, monitoring, and evaluation of higher institutions programmes, infrastructural facilities, teaching and non-teaching staff, and instructional materials. 


\section{B. METHODS}

A quantitative research design was employed for this study, which light on the use of descriptive survey. A research design is a general procedure for carrying out a scientific research. It serves as a guide in the research procedure to gather, analyze, and interpret the data. To provide a more comprehensive picture of each aspect of the research pursue using quantitative research method. According to Hesse-Biber (2010) employed a research design that use quantitative data to answer particular questions. This method generate more comprehensive evidence and help answer questions of the research. The research would use questionnaire based on the Likert scale rating 1-5 to collect data and analyse the collected data. A questionnaire was used in the quantitative study, design based on the five (5) Likert-scale questionnaire (1=Strongly disagree, 2= Disagree, $3=$ Slightly agree, $4=$ Agree and 5= Strongly agree). It serve as research instrument for the quantitative method to acquire data about the studied research, participants and demographic information. Seven Construct measuring quality assurance were formulated each construct contain several items related to the performance assessment of quality assurance (QA) indicators in the Nigerian qualification framework. The staff population of these TVET educational institutions are College of Education Azare has 233 staff, Federal polytechnic Bauchi has 215 staff and Bauchi state polytechnic has 164 staff the total of all staff are 615 , so each school will get the questionnaires based on institution staff divide by Total staff multiply by 100 give Total questionnaires for each institution.

Research Question: What is the level of performance of polytechnics and Technical College in using quality assurance?

\section{RESULT AND DISCUSSIONS}

The tables below shows the result obtained about the staff responses level of performance in each educational institutions from the answered questionnaire using a five Likert scale from the tables as indicated the result are extracted based on the responses of these institutions separately about each construct in the questionnaire separately.

Table 1.

Summary of Indicators Measuring Finance for all Institutions

\begin{tabular}{c|c|c}
\hline Institutions & Overall Mean & Overall SD \\
\hline COE Azare & 3.47 & 0.89 \\
Federal Polytechnic Bauchi & 3.41 & 1.04 \\
Bauchi State Polytechnic Bauchi & 3.49 & 1.11 \\
\hline
\end{tabular}

The table 4.5 shows the Overall mean and Standard deviation SD of indicator measuring finance in the three different institutions, College of Education Azare has overall mean of 3.47 with standard deviation SD of 0.89 , Federal Polytechnic Bauchi has overall mean and overall Standard Deviation SD of $3.41,1.04$, while State Polytechnic Bauchi has overall mean and Standard Deviation SD of $3.49,1.11$. this highlight the State Polytechnic Bauchi has high response about the level of performance indicator measuring finance in quality assurance.

Table 2.

Summary of Indicators Measuring Access for all Institutions

\begin{tabular}{c|c|c}
\hline Institutions & Overall Mean & Overall SD \\
\hline COE Azare & 3.64 & 1.2
\end{tabular}


Federal Polytechnic Bauchi

Bauchi State Polytechnic
3.50

3.40
1.0

1.0

The table 2 shows the Overall mean and Standard deviation of the indicator measuring Access in the three different institutions, College of education Azare has overall mean of 3.64 with standard deviation SD of 1.2, Federal Polytechnic Bauchi has overall mean and overall Standard Deviation SD of 3.50, 1.0, whereas State Polytechnic Bauchi has overall mean and Standard Deviation SD of 3.40, 1.0. This highlight that College of education Azare has high response about the level of performance indicator measuring Access in quality assurance.

Table 3.

Summary of Indicators Measuring Participation for all Institutions

\begin{tabular}{c|c|c}
\hline Institutions & Overall Mean & Overall SD \\
\hline COE Azare & 3.66 & 0.97 \\
Federal Polytechnic Bauchi & 3.57 & 0.83 \\
Bauchi State Polytechnic & 3.60 & 0.86 \\
\hline
\end{tabular}

The table 4.13 shows the Staff Overall mean and Standard deviation of the indicator measuring Participation in the three different institutions, College of education Azare has overall mean of 3.66 with standard deviation SD of 0.97, Federal Polytechnic Bauchi has Overall mean and Overall Standard Deviation SD of 3.57, 0.83, and State Polytechnic Bauchi has Overall mean and Standard Deviation SD of 3.60, 0.86. This highlight the College of education Azare has high response about the level of performance indicator measuring Participation in quality assurance.

Table 4.

Summary of Indicators Measuring Quality for all Institutions

\begin{tabular}{c|c|c}
\hline Institutions & Overall Mean & Overall SD \\
\hline COE Azare & 4.12 & 0.71 \\
Federal Polytechnic Bauchi & 4.26 & 0.87 \\
Bauchi State Polytechnic & 4.14 & 0.75 \\
\hline
\end{tabular}

The table 4.17 shows the Staff Overall mean and Standard deviation SD of the indicator measuring Quality in the three different institutions, College of education Azare has overall mean of 4.12, with standard deviation SD of 0.71, Federal Polytechnic Bauchi has Overall mean and Overall Standard Deviation SD of 4.26, 0.87, and State Polytechnic Bauchi has Overall mean and Standard Deviation SD of 4.14, 0.75. This highlight the Federal Polytechnic Bauchi has high response about the performance indicator measuring Quality in quality assurance.

Table 5.

Summary of Indicators Measuring Innovation for all Institutions

\begin{tabular}{c|c|c}
\hline Institutions & Overall Mean & Overall SD \\
\hline COE Azare & 3.6 & 0.86 \\
Federal Polytechnic Bauchi & 3.8 & 0.90 \\
Bauchi State Polytechnic & 3.5 & 0.81 \\
\hline
\end{tabular}

The table 4.21 shows the staff Overall mean and standard deviation SD of the indicator measuring Innovation in the three different institutions, College of education Azare has overall 
mean of 3.60, with standard deviation SD of 0.86. Federal Polytechnic Bauchi has Overall mean and Overall Standard Deviation SD of 3.80, 0.90. State Polytechnic Bauchi has Overall mean and Standard Deviation SD of 3.5, 0.81. This highlight the Federal Polytechnic Bauchi has high response about the performance indicator measuring innovation in quality assurance.

Table 6.

Summary of Indicators Measuring Policy design for all Institutions

\begin{tabular}{c|c|c}
\hline Institutions & Overall Mean & Overall SD \\
\hline COE Azare & 3.72 & 0.79 \\
Federal Polytechnic Bauchi & 3.86 & 0.84 \\
Bauchi State Polytechnic & 3.91 & 0.85 \\
\hline
\end{tabular}

The table 4.25 shows the Staff Overall mean and standard deviation SD of the indicator measuring Policy design in the three different institutions, College of education Azare has overall mean of 3.72 with standard deviation SD of 0.79. Federal Polytechnic Bauchi has Overall mean and Overall Standard Deviation SD of 3.86, 0.84, whereas State Polytechnic Bauchi has Overall mean and Standard Deviation SD of 3.91, 0.85. This highlight the State Polytechnic Bauchi has high response about the level of performance indicator measuring Policy design in quality assurance.

Table 7.

Summary of Indicators Measuring Program delivery for all Institutions

\begin{tabular}{c|c|c}
\hline Institutions & Overall Mean & Overall SD \\
\hline COE Azare & 3.57 & 0.85 \\
Federal Polytechnic Bauchi & 3.62 & 0.89 \\
Bauchi State Polytechnic & 3.88 & 0.95 \\
\hline
\end{tabular}

The table 4.25 shows the Staff Overall mean and Standard deviation SD of the indicator measuring Program delivery in the three different institutions, College of Education Azare has overall mean of 3.57 , with standard deviation SD of 0.85 . Federal Polytechnic Bauchi has Overall mean and Overall Standard Deviation SD of 3.62, 0.89, whereas State Polytechnic Bauchi has Overall mean and Standard Deviation SD of 3.88, 0.95. This highlight that State Polytechnic Bauchi has high response about the level of performance indicator measuring Program delivery in quality assurance.

Table 8.

Overall Summary of All Construct Quality Assurance Indicators

\begin{tabular}{c|c|c|c|c|c}
\hline Institution & $\begin{array}{c}\text { Total } \\
\text { mean }\end{array}$ & $\begin{array}{c}\text { Total } \\
\text { SD }\end{array}$ & $\begin{array}{c}\text { Low } \\
3.5-3.59\end{array}$ & $\begin{array}{c}\text { Medium } \\
3.6-3.69\end{array}$ & $\begin{array}{c}\text { High } \\
3.7-3.8\end{array}$ \\
\hline College of Education Azare & 3.68 & 0.89 & & $\checkmark$ & \\
Federal Polytechnic Bauchi & 3.71 & 0.91 & & & $\checkmark$ \\
State Polytechnic Bauchi & 3.80 & 1.00 & & & $\checkmark$ \\
\hline
\end{tabular}

The table 4.30 Summarizes the study findings regarding the level of performance of polytechnics and technical colleges, after summing the overall mean and standard deviation SD of seven constructs of quality assurance indicators (Finance, Access, Participation, Quality, Innovation, Policy design, and Program delivery). Participant are categorized based on low, medium and high, the table highlight that State Polytechnic Bauchi and Federal Polytechnic Bauchi has high 
level while College of education Azare has medium level of performance to quality assurance indicators.

\section{CONCLUSION}

The system of measuring and valuing knowledge mostly do not involve prices, academic capitalism is not the principal driver of global comparison. The performance assessment of polytechnics and technical colleges in Bauchi state is to draw financial value from knowledge and sharpening the performance between the TVET institutions in Bauchi about the needs for Quality Assurance in the institution. Therefore this project sets against performance assessment of Bauchi polytechnics and technical colleges using Quality Assurance indicators in Nigeria qualification framework. (1) To determine the level of performance of polytechnics and technical colleges using Quality Assurance (QA) indicators, and (2) To determine if any, differences between the level of usability of quality assurance within institutions.

Based on this intent, the literature was explored for deeper insight on TVET institutions and Quality Assurance. For data gathering however, a structured questionnaire with seven (7) constructs each contain some items was administered to a sample of 60 respondents using cluster sampling technique in the three different institutions in Bauchi state Nigeria. The findings from the inferential statistics carried out were instructive. This shows that State Polytechnic Bauchi and Federal Polytechnic Bauchi has high level of performance based on responses using Likert scale rating of Strongly disagree, Disagree, Slightly agree, Agree and Strongly agree to quality assurance indicators in Nigeria qualification framework. College of Education Azare has medium level of performance of quality assurance indicators. These findings can be adapted by any institution in any region that have similar situations and conditions such as in Southeast Asia

\section{Recommendations}

Performance Assessment of any type, be it inspection, supervising, validation or auditing, has no value if it is carried out without any account being taken of the policy framework and context within an aspect of education is being conducted. The foregoing, the need for quality assurance in vocational education cannot be over emphasized as the performance indicators of the programme still leave so much to be attended to in answering the numerous questions of quality of output, Considering the value of quality vocational education the following are the recommendation based on this study:

1. The Quality assurance unit should be made aware to every member of staff in the institution to enable him/her benefits from the unit services.

2. The potential of higher education quality assurance systems in Nigeria is to fulfil the improvement of institution responsibility is frequently dissatisfied by long standing problems of finance, efficiency, tools and equipment, equity, and quality, government or management, need to be improve.

3. Strategic plan for institutions quality assurance in education and training adopted been the vehicles of cooperation. Will be Improve so that quality and efficiency of education and training among the workers would be improved.

4. Quality assurance unit can lead to effectiveness of teaching, resulting to school alteration which is needed for a standard shift towards world class that will develop the students quality, potentiality, creativity and innovations from there lecturers through the unit should be make mandatory to every institution. 
5. The authorities should be able to create time to find out from research findings what new ideas are discovery that can help to make huge contributions to their practical approaches, since information from new ideas should be maximize to development and progress of higher institutions.

6. The imperativeness of the researchers in education sector to publish specialist's oriented findings should be a priority issue to educational researchers in the sector so quality assurance need to supervise and direct the unit to encourage research.

7. Federal government should give more funding and employ more staff to cater the need of quality assurance unit in each higher institution.

8. All educational institution must frequently organize workshop and awareness campaign about the significant of quality assurance unit/division in their institutions.

9. Federal government should monitor all the quality assurance in TVET institutions particularly Bauchi state to ensure proper use of resources and programmed delivery.

10. The Bauchi state government should intervene in the institutions through assisting them with facilities, tools, fund etc. to help them maintain standard in the state institutions. 


\section{References}

Adebakin, M. A.,\& Raimi, L. (2012). National Security Challenges and Sustainable Economic Development: Evidence from Nigeria. Journal of Studies in Social Sciences, Vol. 1 (1), pp. $1-30$.

Akhuemonkhan, I. A. and **Raimi, L. (2013). impact of quality assurance on technical vocational education and training (tvet) in Nigeria Yaba College of Technology, Lagos, Nigeria

Adegoke, K.A. (2002). Standard in teacher preparation in Nigeria: some highlights. Journal of Education for National development (JOEND), Vol. 4 No. 1 and 2. Unique Educational Publishers 1-6.

Afeti, G. (2010). Technical and vocational education and training for industrialization. Retrieved from http://www.arrforum.org/publication/occasional-papers/40/95-technical-andvocational-education-andtrainig-for-industrialisation.html. Retrieved on 23/12/2012.

Alele Williams. (2004). 'Developing an African higher education quality rating system'.

Alfred, S.B., \& Kayoma, F. O. (2012). Enhancing the quality of vocation agriculture in secondary schools for agricultural productivity in Nigeria. Proceedings of the 2012 Annual International Conference of the Faculty of Education, Delta State University Abraka. 99103.

Ahmed, T. (2001). Revamping Our National Economy through Technical Vocational Education and Training (TVET). Available: http://www.nigerianbestforum.com/blog/revamping-ournationa economy-through-technical-vocational-education-and-training-tvet/(Accessed:8 September, 2013).

Amadike, O. (2007). Relationship Between Training and Employment of Technical College Graduates in Oyo State between 1998 and 2001. Unpublished Ph.D. Thesis. University of Ibadan, Ibadan, Nigeria.

Ambrose U. (2003). Nigeria spends N1.2trn annually on ICT goods import. Manufacturing Today February 25 Edition. http://www.manufacturingtodaynigeria.com/index.php/latestnews/150-news/6266-nigeria-spends-n12trn-annually-on-ict-goods-import (Accessed: 12 May, 2013).

Ajayi, P. O. (2007). Evaluation of the implementation of senior secondary school

Physics curriculum in south west Nigeria. Unpublished Ph. D thesis. University of Ado-Ekiti, Nigeria.

Badawi, A. A. (2013). TVET and entrepreneurship skills (Chapter 8). In Revisiting global trends in TVET: Reflections on theory and practice. UNESCO-UNEVOC International Centre for Technical and Vocational Education and Training.

Ball, S.J. (1994). Researching inside the state: Issues in the interpretation of elite interviews. In Halpin, D. and Troyna, B. (eds.) Researching Education Policy: Ethical and methodological issues. London, Falmer Press. 
Baker, G. (2002). Human Capital: A Theoretical and Empirical Analysis with Special Reference to Education. Chicago: The University of Chicago Press.

Cheng, Y. C. (2001). Paradigm Shifts in Quality Improvement in Education: Three Waves for the Future, Speech Presented at The International Forum on Quality Education for the Twenty-first Century, Beijing, China, and 12-15 June.

Crosby P.B. (1979). Quality is Free. New York, McGraw-Hill.

Creswell. (2010), Research design qualitative, quantitative, and mixed methods approaches, university of Nebraska -Lincoln, Sage publications. 